SLOVO, sv. 70 (2020), 117-136, Zagreb 2020.

Johannes REINHART

UDK 272-282.7:003.349.1

Wien

johannes.reinhart@univie.ac.at

272-732.2Clemens Romanus, sanctus

Izvorni znanstveni članak

Primljen: 1. travnja 2019.

Prihvaćen: 9. listopada 2019.

\title{
HRVATSKOGLAGOLJSKO BREVIJARSKO ŽITIJE PAPE KLEMENTA RIMSKOGA*
}

\begin{abstract}
Žitije pape Klementa I. sačuvano je u ograničenom broju hrvatskoglagoljskih brevijara. Dvaput je izdano prema jednome od najstarijih tekstova, iz Vrbnickog 4. brevijara (XIV. st.), jednom u izdanju Josefa Vajsa (1911.), a drugi put u izdanju Sobolevskoga (1912.). Osim toga, Žitije je sačuvano u sljedećim brevijarima ili fragmentima brevijara: Brevijar Illirico 6 (sredina / treća četvrtina XIV. stoljeća), Ljubljanski brevijar (kraj XIV. stoljeća), Pašmanski brevijar (XIV./XV. stoljeće), Oxfordski Brevijar-Missal Nr. 172 (XIV. stoljeće), Mavrov brevijar (1465. g.), Kukuljevićev brevijar (1485. g.), Prvotisak brevijara (1491.); List brevijara (XIV./XV. stoljeće, Krk, br. 39), List brevijara (XV. st., Berčićeva zbirka 1.13, f. 19). Samo je u nekima od ovih tekstova potvrđeno svih devet čitanja Žitija.

Sobolevskij je u svom članku s pravom ustvrdio da se izvornik staroslavenskog teksta mora naći u latinskom brevijaru. Vajs je objavio latinski tekst iz suvremenog brevijara, koji se značajno razlikuje od hrvatskoglagoljskoga. Istraživanje oko dvadesetak rukopisa i starih tiskanih izdanja latinskog brevijara u Beču i Zagrebu, nažalost, nije rezultiralo otkrićem pravog latinskog izvornika teksta na hrvatskoj glagoljici. Najvjerojatniji izvornik potencijalno je Breviarium de Camera secundum morem sanctae Romanae Ecclesiae (Venecija 1521.), koji se koristi i u Rječniku crkvenoslavenskoga jezika hrvatske redakcije u Zagrebu.

Vajs je u svom članku istaknuo niz morfoloških (npr. arhaični aorist), sintaktičkih (nominativ / akuzativ, adnominalni dativ) i leksičkih (apostolikb, eterb) arhaizama hrvatskoglagoljskoga teksta (»da stavimo ovaj tekst uporedo sa najstarijim glagoljskim tekstovima uopće «). No, budući da Vita također sadrži niz gramatičkih inovacija (npr. instrumental apsolutni) i tipično hrvatskih leksema (npr.: očito /publicel 'javno'; prijedložna skupina otb + genitiv 'o'), može se pretpostaviti da je tekst Vitae preveden krajem XIII. ili početkom XIV. stoljeća.
\end{abstract}

Ključne riječi: Papa Klement Rimski, hrvatskoglagoljski brevijari, latinski izvornik, brevijarsko Klementovo Žitije, jezični arhaizmi, jezične inovacije, vrijeme nastanka Klementova Žitija

* Zahvaljujem Arhivu Hrvatske akademije znanosti i umjetnosti (HAZU) i Metropolitani u Zagrebu, kao i Rukopisnome odjelu Austrijske nacionalne knjižnice u Beču - što su mi omogućili korištenje rukopisa i starih tiskanih izdanja. Staroslavenskome institutu u Zagrebu zahvaljujem za mogućnost uporabe kopija rukopisnih hrvatskoglagoljskih brevijara, te napose za susretljivu pomoć njegovih djelatnika u pripremi moga konferencijskog izlaganja: Milanu Mihaljeviću, Ljiljani Mokrović, Ani Šimić i Jozi Veli. 


\section{UVOD}

Klement Rimski (Clemens Romanus) bio je treći nasljednik sv. Petra na Rimskoj stolici (92. - 101. g.). ${ }^{1}$ Njegov je jedini autentični spis Poslani-

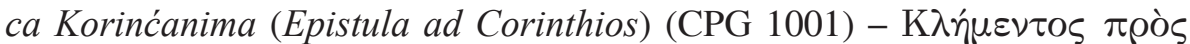
Kopıvíous, nastala 95. - 96. g. na grčkom jeziku, prevedena na latinski (FREDE 1995: 384, s.v. CLE-R), sirijski i koptski. Vijesti o papi Klementu I. saznajemo iz Pseudoklementina (CPG 1015), ponajprije iz Klementova romana u deset knjiga Recognitiones, koji se očuvao samo u latinskom prijevodu (BHL 6644-6645).

Sadržajnih podudaranja između Pseudoklementina i brevijarskog Žitija sv. Klementa, koje je tema ovoga članka - nema, usp.: »Die Nachrichten über seine Verbannung nach dem Taurischen Chersones und über seinen Martertod in den Fluten des Schwarzen Meeres sind Legenden (4. Jh.)« (ALTANER; STUIBER 1993: 45). U prijevodu: »Vijesti o njegovu progonu u tavričeski Herson i mučeničkoj smrti u valovima Crnog mora su legendarne.« Međutim, upravo progon i mučenička smrt svetca čine glavni sadržaj brevijarskoga Žitija.

U slavistici je dobro poznat Konstantinov (Ćirilov) prijenos njegovih moći s Krima u Rim u IX. stoljeću. ${ }^{2}$

\section{2. ŽITIJE PAPE KLEMENTA I. U HRVATSKOGLAGOLJSKIM BREVIJARIMA}

Žitije pape Klementa I. potvrđeno je u ograničenom broju hrvatskoglagoljskih brevijara i fragmenata XIV. i XV. stoljeća. To su izvori: IV. vrbnički brevijar iz XIV. st., $\left(=\mathrm{BrVb}_{4}\right)$ 91rb23-93rb1; Vatikanski brevijar Illirico 6 iz 1379. g. $\left(=\right.$ BrVat $\left._{6}\right)$ 204ra31-205ra15; I. ljubljanski brevijar (br. 161) s kraja XIV. st. (= BrLab) 158va8-159va29; Oxfordski brevijar-misal Canon. liturg. 172 iz XIV. st. (= BrOxf) 366vb22-367rb17; Pašmanski brevijar iz XIV./XV. st. (= BrPm) 283rb30-284ra31; Brevijar popa Mavra iz 1465. g. (= BrMavr) 135rb12-136va2; Kukuljevićev brevijar iz 1485. g. (= BrKuk) 135rb12136va28; Prvotisak brevijara iz 1491. g. (= BrPt) 341c-342a; List brevijara iz Berčićeve zbirke (1.13: l. 19) iz XV st. (= FgBerč) 1. 19; Čtenije 5-9 i List brevijara iz Arhiva bivšse Staroslavenske akademije u Krku (br. 39) iz XIV.I XV. st. (= FgKrk) »do sredine 6. štenja (ŠTEFANIĆ 1960: 206-207).

Tekst Klementova Žitija izdan je prije više od sto godina prema $\mathrm{BrVb}_{4}$ dva puta: prvotno u izdanju Josefa Vajsa (VAJS 1911) te prema njemu i A. I. So-

1 Usp. SAXER 1994.

2 Usp. TRENDAFILOV 2003. 
bolevskoga (SOBOLEVSKIJ 1912). ${ }^{3}$ Upotrebom većega broja hrvatskoglagoljskih prijepisa Žitija i usporedbom njihova sadržaja s Klementovim Žitijem u latinskim brevijarima pokušat ću odrediti vrijeme njegova prijevoda.

Neki hrvatskoglagoljski brevijari ne sadrže svih devet lekcija izdanoga teksta iz $\mathrm{BrVb}_{4}$. Inventar čitanja u hrvatskoglagoljskim brevijarima možemo prikazati na sljedeći način:

Izdani tekst iz $\mathrm{BrVb}_{4}$ ima devet lekcija:

Čtenie I. Inc. Klimbn'tb o $o^{t}$ negože $P(a) v(a) l b$ ap (osto)lb k pilipisiem ' piše g(lago)letb

Čtenie II. Inc. Kliman 't' rodom' rimlanin $o^{t}$ strani Celie gori $o^{t} o(t b) c a$ Fauština sědě lět'.z. (=9) m(ě)s(e)ca.b. $(=2) d(b) n e . i ̈ . ~(=10)$.

Čtenie III. Inc. Si stvori v sedbm stranb razděti (!) pisci izbrane věrne crkvenie.

Čtenie IV. Inc. Klimbnt' ap (osto)likb etera muža prošeniem 'ženi ego Těodora oslěpbl'ša i oglbg'ša (!) za prěgrěšenie ego zdrava stvoriv.

Čtenie V. Inc. Pisanie že sice g(lago)laše. vižd'c(ěsa)ru ěko Klimbnt'ezik' naš'sbblažnaet'.

Čtenie VI. Inc. Veliku že blagodět' g(ospod)b Klimbn tu tako poda ěko plakati se sudiju stvori i g(lago)lati.

Čtenie VII. Inc. On že otveĉa. ne moimi utežani g(ospod)b posla me $k$ vam'. i vašimb oběn 'čanim' pričestna me stvori.

Čtenie VIII. Inc. Egdaže m(o)l(i)tvb isplbni. v'zrěv'vidě na gorě agnbc' $b(o) z ̌ i$ stoeĉ́'.

Čtenie IX. Inc. Sim že bivajuĉem 'stoěhu mnozi h(rbst)běne na brězě mora plačucie se.

Ista čitanja imaju BrLab, BrKuk te BrVat ${ }_{6}$ u kojemu su ona drukčije raspoređena. Iako je Žitije u BrPm i BrMavr također raščlanjeno na devet čitanja, u tim je brevijarima potvrđen znatno manji dio Klementova Žitija. Naime, deveto čitanje u BrPm odgovara petom čitanju potpunih brevijara, a deveto čitanje u BrMavr odgovara šestom čitanju potpunih brevijara. BrOxf ima samo dva prva, a BrPt iz 1491. šest čitanja, među kojima šesto odgovara šestom

3 De Santos Otero je razmotrio hrvatskoglagoljsko brevijarsko Žitije u svojoj knjizi o slavenskim apokrifima u poglavlju o Pseudo-Klementinama (DE SANTOS OTERO 1978: 140 146 , posebno str. 143 , br. $8 \mathrm{~s}$ bilj. 142). 
čitanju potpunih brevijara. FgBerč sadrži samo lekcije 5-9 (usp. VJALOVA 2000: 13-14), dok FgKrk sadrži samo tekst »do sredine 6. štenja« (ŠTEFANIĆ 1960: 206-207).

U tekstološkom su pogledu - o čemu će biti još govora - hrvatskoglagoljski tekstovi brevijarskoga Žitija pape Klementa I. razmjerno jedinstveni. Nasuprot tome, u konzultiranim se latinskim brevijarima ${ }^{4}$ primjećuje velika raznolikost lekcija na blagdan svetoga pape sv. Klementa. U mnogim brevijarima uopće nema lekcija u njegovoj službi. Ali i u rukopisima gdje postoje, uočava se veliko šarenilo.

Osim spomenutih rukopisa i tiskanih izdanja, konzultirao sam i neke digitalizirane rukopise s interneta, među kojima i nekoliko iz zaklade Lilienfeld (www.manuscripta.at).

\section{3. ŽITIJE PAPE KLEMENTA I. U LATINSKIM BREVIJARIMA}

Iako većina od devet hrvatskoglagoljskih lekcija brevijara ima paralele u latinskim rukopisnim i tiskanim brevijarima, izvornike nekih lekcija nisam uspio pronaći. S obzirom na stupanj podudaranja njihovih lekcija na blagdan sv. Klementa s hrvatskoglagoljskim brevijarima, latinski se brevijari mogu podijeliti na sljedeće skupine:

(a) brevijari bez lekcija: Berlin, Ms. lat. oct. 402 (1132. g.) (WADDELL 2007); Troyes, Ms. 2030 (1247. g.) (MAÎTRE 2015); Breviarium Zagrabiense (MR 80) (XIV./XV. st.); Breviarium Ecclesiae cathedralis Zagrabiensis (MR 67) (XIII. st.).

(b) brevijari s lekcijama koje se ne slažu s lekcijama hrvatskoglagoljskih brevijara: Brevijar MR 72/2 (XIII. st.), u kojemu se nalazi 9 vrlo krat-

4 Zasad sam uspio pregledati samo stare rukopisne i tiskane brevijare u Beču i Zagrebu. U Austrijskoj nacionalnoj knjižnici u Beču pregledao sam stara tiskana izdanja rimskoga brevijara: I. Breviarium romanum - Venecija 1478. g. pod sign. Ink 4.D.10, Venecija 1481. g. pod sign. Ink 21.D.2, Albi 1482. g. pod sign. Ink 5.D.2 i Lyon 1559. g. pod sign. 22.J.55; II. Breviarium romanum optime recognitum - Venecija 1558. g. pod sign. 22.G.51. U zagrebačkoj Metropolitani pregledao sam sljedeće rukopise: I. Breviarium Zagrabiense, MR 80, iz XIV./XV. st. (KNIEWALD 1940: 72-73); II. Breviarium s. Justina, MR 72/II, iz XIII. st. (KNIEWALD 1940: 66-68; BADURINA 1995: 104, № 240); III. MR 29 iz XIV./XV. st. (KNIEWALD 1940: 76-79); IV. Breviarium Ecclesiae cathedralis Zagrabiensis, MR 67, iz XIII. st. (KNIEWALD 1940: 68-72). U Arhivu HAZU u Zagrebu pregledao sam: I. Breviarium Zagrabiense pod sign. I. c. 42 iz XIV. st. (KNIEWALD 1940: 89-90; BADURINA 1995: 99; № 201); II. Breviarium pod sign. I. a. 11. iz XV. st. (KNIEWALD 1940: 90-92; BADURINA 1995: 99; № 202); III. Breviarium fratrum minorum pod sign. I. a. 8. iz XIV. st. (KNIEWALD 1940: 95-96; BADURINA 1995: 100, № 205). 
kih lekcija, i Brevijar MR 29 (XIV./XV. st.), u kojemu se nalaze 3 lekcije.

(c) brevijari sa 6 lekcija, od kojih se samo manji broj slaže s lekcijama hrvatskoglagoljskih brevijara: Brevijar HAZU I. a. 11. (XV. st.) u kojem se 5. i 6. slažu s hrvatskoglagoljskima i tiskani Breviarium romanum (Venecija 1481. g.) u kojem se s hrvatskoglagoljskima slaže polovica.

(d) brevijar koji se velikim dijelom slaže s hrvatskoglagoljskim brevijarima, ali ima i različite lekcije: tiskani Breviarium de Camera secundum morem sanctae Romanae Ecclesiae (Venecija 1521. g.) koji sadrži 6 lekcija, od kojih se samo 3. lekcija ne slaže s onom u hrvatskoglagoljskim brevijarima. $^{5}$

Kao primjer složenih odnosa između latinskih i hrvatskoglagoljskih brevijara navodim incipite lekcija iz tiskanoga brevijara iz grada Albi u Francuskoj koji je izašao 1482. godine:

I. Inc. Clemens de quo apostolus paulus ad philippenses scribens ait.

II. Inc. Scripsit ex persona romane ecclesie ad ecclesiam corinthiorum valde utilem epistulam.

III. Inc. Sed et mult(is) de eadem epistula non solum sensibus sed iux(ta) verbo(rum) quem ordinem abutitur.

IV. Inc. Clemens natione romanus de regione celio monte ex patre Faustino. sedit annos .ix. menses .ij. dies .x.

V. Inc. Hic fecit septem regiones diuidi notariis fidelibus ecclesie. qui gesta martyrum sollicite et curiose unusquisque per regionem suam perquireret.

VI. Inc. Ideo Linus et Cletus ante eum proscribuntur qui ab ipso principe apostolorum principe (?) ad ministerium sacerdotale exhibendum sunt episcopi ordinate etc.

Lekcije 1. i 2. ovoga latinskoga brevijara odgovaraju I. čteniju hrvatskoglagoljskoga brevijara, njegova 4. lekcija odgovara II. hrvatskoglagoljskome čteniju, a 5. lekcija III. čteniju.

Nisam uspio pronaći ni u jednom latinskom brevijaru 4. lekciju koja govori o ozdravljenju Teodorina muža, iako iz drugih izvora znamo da se zvao Sisinije. S druge strane, u nekim latinskim brevijarima ova epizoda zauzima

5 Ovaj se brevijar koristi kao izvor u Rječniku crkvenoslavenskoga jezika hrvatske redakcije (RCJHR I i II). 
znatno više prostora - kao i u pariškom izdanju Žitija (Sanctuarium seu Vitae sanctorum) kojim sam se služio, a koje su 1910. g. priredili benediktinci iz opatije Solesmes (MOMBRITIUS 1910). Riječ je o djelu koje je oko 1482. god. izdao Mombritius, Bonino Mombrizio (1424.-1482./1502. g).

\section{TEKST ŽITIJA PAPE KLEMENTA I. U STARIM LATINSKIM ANTIFONIMA}

Budući da dosad nisam uspio pronaći nijedan latinski brevijar sa Žitijem Pape Klementa I. stariji od razvijenog Srednjega vijeka, svjedočanstvo o tom tekstu u starim latinskim antifonama iz XII. stoljeća koje je izdao Hesbert (HESBERT 1963 i HESBERT 1968) veoma je važno. Usporedba incipita tih antifona s tekstovima latinskih lekcija i hrvatskoglagoljskih čtenija pokazuje da su bliži tekstu latinskoga i hrvatskoglagoljskoga brevijara nego Mombritiusovu Žitiju u Sanctuarium seu Vitae sanctorum:

qua pede dextro erecto: quasi locum sancto clementi ostenderet: ... qui suo impetu euomens fluuium fecit. ... fluminis impetus laetificat ciuitatem dei. (MOMBRITIUS 1910: $344.8+14,15-16)^{6}-(2122$.) De sub cujus pede fons vivus emanat, fluminis impetus laetificat civitatem Dei. - Čtenie VIII. Egdaže m(o)l(i)tvb isplbni. v'zrěv' vidě na gorě agnbc'b(o)ži stoeĉ'. Pod negože nogoju istočnikb živ'isteče. ... Rěčna ustr'mleniě veselet gradb b(o)ži (Ps 45,5)

Non meis meritis ad uos me misit dominus et ad hanc uestram coronam adduxit: (MOMBRITIUS 1910: 343.58-344.1) - (3924.) Non meis meritis ad vos me misit Dominus, ad vestras coronas participem me fieri. - Čtenie VII. On že otveĉa. ne moimi utežani g(ospod)b posla me k vam'. i vašimb oběn 'čanim 'pričestna ne (vl. me) stvori.

omnes gentes uicinae crediderunt dominum Iesum christum: (MOMBRITIUS 1910: 344.39-40) - (4124.) Omnes gentes per gyrum crediderunt Christo Domino. - Čtenie IX. I togo radi sucei okrbst'vèrovaše v' g(ospod)a $n($ a) šego Is (u)h(rbst)a.

$\varnothing$ (MOMBRITIUS 1910: 344.7) - (4180.) Orante sancto Clemente, apparuit ei Agnus Dei. - Čtenie VII. Moleĉu že se s(ve)tomu Klimbn'tu ěvi se eтu agnbc'b(o)ži.

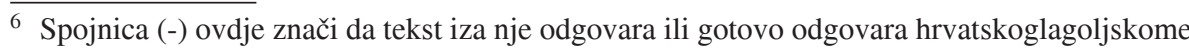
tekstu. 
uidit agnum stantem: qua pede dextro erecto: ... qui suo impetu euomens fluuium fecit. (MOMBRITIUS 1910: 344.7-8 + 16) - (5408.) Vidi (vl. Vidit) supra montem agnum stantem, de sub cujus pede fons vivus emanat. - Čtenie VIII. vidě na gorě agnbc'b(o)ži stoeĉ́. Pod negože nogoju istočnikb živ'isteče

\section{TEKSTOLOGIJA LEKCIJA LATINSKOGA BREVIJARSKOG ŽITIJA}

Za istraživanje brevijarskoga teksta važno je i samo Žitije (Vita sancti Clementi; u pariškom izdanju iz 1910. g.: »Passio sancti Clementis papae et martyris«) koje je objavio Mombritius - BHL 1848, iako se njegov tekst ne slaže uvijek s tekstom lekcija latinskoga brevijarskoga Žitija. Kako je ustanovio germanist Gerhard Eis (EIS 1933), neka Mombritiusova Žitija (Vitae sanctorum), između ostalog i Klementovo, potječu iz Magnum legendarium austriacum iz XII. stoljeća (EIS 1933: 45 slj.).

Prve su dvije lekcije latinskoga brevijarskoga Žitija - o čemu svjedoče neki latinski rukopisi i stara tiskana izdanja latinskoga brevijara - znatno starije od ostalih. Prva je lekcija preuzeta iz Jeronimova spisa De viris illustribus (CPL: 616):

XV. Clemens, de quo Apostolus Paulus ad Philippenses scribens, ait, Cum Clemente et caeteris cooperatoribus meis, quorum nomina scripta sunt in libro vitae (Philip. IV, 3), quartus post Petrum Romae episcopus: siquidem secundus Linus fuit, tertius Anacletus, tametsi plerique Latinorum, secundum post Petrum Apostolum putent fuisse Clementem. Scripsit ex persona Romanae Ecclesiae ad Ecclesiam Corinthiorum valde utilem Epistolam, quae et in nonnullis locis publice legitur, quae mihi videtur characteri Epistolae, quae sub Pauli nomine ad Hebraeos fertur, convenire. Sed et multis de eadem Epistola, non solum sensibus, sed juxta verborum quoque ordinem abutitur. Omnino grandis in utraque similitudo est. Fertur et secunda ejus nomine Epistola, quae a veteribus reprobatur. Et Disputatio Petri et Appionis longo sermone conscripta, quam Eusebius in tertio historiae Ecclesiasticae volumine coarguit. Obiit tertio Trajani anno, et nominis ejus memoriam usque hodie Romae exstructa Ecclesia custodit.

Drugo je čitanje preuzeto iz Liber pontificalis (Epitome Feliciana, IV. poglavlje) (CPL: 1568):

IIII. CLEMENS, natione Romanus, de regione Celio monte, ex patre Faustino, sedit ann. VIIII mens. II dies X. Fuit autem temporibus Galbe et Ves- 
pasiani, a consulatu Tragali et Italici usque ad Vespasiano VIIII et Tito. Martyrio coronatur. Hic fecit VII regiones et diuidit notariis fidelibus ecclesiae, qui gesta martyrum sollicite et curiose unusquisque per regionem suam diligenter perquireret; et fecit duas epistolas. Hic fecit ordinationes III, presb. X, diac. II, episcopos per diuersa loca V per mens. Decemb. Obiit martyr III Traiani. Qui sepultus est in Grecias VIIII kl. Decemb. Et cessauit episcopatus dies XXI. ${ }^{7}$

Tekst je ostalih lekcija latinskoga brevijara više-manje preuzet iz potpunog teksta Muke sv. Klementa (Passio S. Clementis) koja je nastala u IV. ili u V. stoljeću, ${ }^{8}$ a izdao ju je Mombritius.

Postanak latinskog spisa Muke Svetog Klementa najčešće se datira u IV. stoljeće $^{9}$ i to na temelju indirektnih dokaza, jer najstariji sačuvani rukopis, iz Opatije St. Gallen, potječe tek iz VIII. stoljeća. ${ }^{10}$ Jedan dokaz u prilog toj dataciji spomen je pojedinosti iz Muke kod starih autora (npr. kod Grgura iz Toursa iz VI. stoljeća), a drugi je jezik Muke (npr. izraz »comes sacrarum « - u brevijaru ne dolazi - nije u prvim stoljećima oprimjeren). ${ }^{11}$

\section{TEKSTOLOGIJA HRVATSKOGLAGOLJSKOGA BREVIJARSKOG ŽITIJA}

Ako se usporedi tekst Žitija u hrvatskoglagoljskim brevijarima, mogu se ustanoviti neka tekstualna podudaranja među pojedinim rukopisima. Na nekoliko mjesta $\mathrm{BrVb}_{4}$ čuva izvorni tekst:

$\mathrm{BrVb}_{4}$ 91va15 kar'terice ep(isto)lie] = BrKuk 135rb29 (kartorice), BrOxf 367ra17] BrVat ${ }_{6}$ 204rb8 pisma karterce (!) ep(isto)lie] BrLab 158va26-27 pis'ma kar 'torice ep (isto)le ] = BrPm 281va18-19 (karterice)] BrMav 309rb13-14] BrPt 341c pisma karterice epistolie - characteri Epistolae

$\mathrm{BrVb}_{4}$ 92ra17-18 her'sonsku] = BrMav 309vb1-2, FgBerč 19ra1] BrVat 204va7 heronsku] = BrKuk 135vb15-16, BrPm 282ra9-10] BrLab 159ra3-4 heronisku] BrPt 342a herunsku

\footnotetext{
${ }^{7}$ Završetak (od riječi »Hic fecit ordinationes « do kraja) u brevijarima nedostaje.

${ }^{8}$ KOROLËV 2014: 437.

$9 »$ Thus, the text of Martyrium Clementis was written not before the very end of fourth century, but not later than AD 500« (KASHTANOV; KOROLËV; VINOGRADOV 2018: 211).

${ }^{10}$ KOROLËV 2014: 434; KASHTANOV; KOROLËV; VINOGRADOV 2018: 203.

${ }^{11}$ KOROLËV 2014: 437.
} 
Ali u tekstu $\mathrm{BrVb}_{4}$ ima i inovacija ili čak pogrešaka:

$\mathrm{BrVb}_{4}$ 91 va6-9 aĉesiimnozěhblatin'skihbdruzěhbza Petrom 'ap (osto)loms mnetb bivše prěžde Kliman 'ta] = BrLab 158va18-21, BrVat ${ }_{6}$ 204rb24 (bivša), BrOxf 367ra6-9, BrPm 283va9-13 (biv'šihb), BrKuk 135rb21-24 (prěžde biv'ša Kliman ta), BrMav 309rb5-8] BrPt 341c Açe že i mn(o)z(i)hb latinskihb druzihb za Petromb apustolomb mnetb bivše prižde Klimanta - tamen etsi plerique latinorum secundum post petrum apostolum putent fuisse clementem

$\mathrm{BrVb}_{4}$ 91vb3 razděti] BrLab 158vb5 razděliti $]=$ BrVat $_{6}$ 204rb18, BrPm 281vb4, BrKuk 135va10-11, BrMav 309rb27 - diuidi

$\mathrm{BrVb}_{4}$ 93ra4 sidro] = BrKuk 136va6-7, FgBerč 19vb21] BrVat ${ }_{6} 204 \mathrm{vb35}$ ankoru $]=$ BrLab 159va10 -11

$\mathrm{BrVb}_{4}$ 93ra4 v krai] $=$ BrKuk 136va7] BrVat $_{6}$ 204vb35 vskrai $]=$ BrLab 159va11, FgBerč 19vb21-22

$\mathrm{BrVb}_{4}$ 93ra6 vi (!) se] BrVat ${ }_{6}$ 204vb36 ěvi se] = BrLab 159va12, BrKuk 136va8-9, FgBerč 19vb24

$\mathrm{BrVb}_{4}$ 93ra7-8 vprorečeno $]=$ BrLab 159va13-14] BrVat ${ }_{6}$ 205ra1-2 vspror(e)čeno] $=$ BrKuk 136va10, FgBerč 19vb26

Tekst je FgBerč najbliži tekstu u $\mathrm{BrVb}_{4}$ :

$\mathrm{BrVb}_{4} 92 \mathrm{va} 27$ per'hi (!)] = FgBerč 19va13] BrVat ${ }_{6}$ 204vb13 heronski] BrKuk 136rb9 horunski

$\mathrm{BrVb}_{4}$ 92va27 pritěše $]=$ FgBerč 19va13] BrVat ${ }_{6} 204 \mathrm{vb} 13$ priteče $]=\mathrm{Br}-$ Lab 159rb20, BrKuk 136rb9-10 - confluens (omnis provincia)

Uočavaju se i podudaranja još nekih brevijarskih tekstova Klementova Žitija - npr. BrPm i BrKuk (ali nisu jedina, već se odnose i na ostale brevijare):

$\mathrm{BrVb}_{4}$ 91va23 Galba $]=$ BrVat $_{6}$ 204rb12-13, BrOxf 367ra25, BrMav 309rb19-20] BrKuk 135va3 Gal'bana] = BrLab 158va33, BrPm 281va26 - Galbe

$\mathrm{BrVb}_{4}$ 91vb16 ěže $]=$ BrVat $_{6}$ 204rb26, BrLab 158vb16] BrMav 309va8 $k a$ ] BrKuk 135va22 ěkože $]=\mathrm{BrPm} 281 \mathrm{vb} 15, \mathrm{BrPt} 341 \mathrm{c}$

$\mathrm{BrVb}_{4}$ 92ra12 napisa $=$ BrLab 158vb34, BrMav 309va27] BrVat ${ }_{6} 204 \mathrm{va} 4$ pisa $]=$ BrKuk 135vb11, BrPm 282ra4

Osim toga potvrđena su i podudaranja BrLab i BrKuk, koja također nisu jedina: 
$\mathrm{BrVb}_{4}$ 92ra22-23 prosilb] $=$ BrVat $_{6}$ 294va10, BrPm 282ra14, BrMav 309vb6, FgBerč 19ra6-7] BrKuk 135vb20 priělb] = BrLab BrLab 159ra7 - petere

$\mathrm{BrVb}_{4}$ 92ra27 obratiti] = BrPm 282ra17, BrMav 309vb9] BrVat $_{6} 204 \mathrm{va} 13$ obrati (!)] = BrLab 159ra10-11, BrKuk 135vb23-24, BrPt 342a

$\mathrm{BrVb}_{4}$ 92rb26-27 pričestna me stvori] = BrVat $_{6}$ 204va30] BrKuk 136ra1516 pričestnika me stvori $]=$ BrLab 159ra32, FgBerč 19rb11-12

Nažalost, navedena podudaranja samo su djelomice identična (npr.: određeni se prijepis na nekom mjestu podudara s jednim ili s nekoliko prijepisa, a već na drugom - s nekim drugim ili s nekoliko drugih), tako da ne možemo sastaviti stemma codicum.

\section{JEZIK HRVATSKOGLAGOLJSKOGA BREVIJARSKOG ŽITIJA}

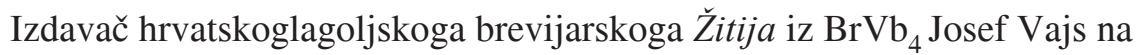
temelju jezične analize teksta došao je do zaključka da nam ona omogućuje »da stavimo ovaj tekst uporedo sa najstarijim glagolskim tekstovima uopće« (VAJS 1911: 565). Tomu u prilog navodi sljedeće lingvističke značajke:

(1) nominalni (kratki) oblici pridjevske deklinacije (H(rbsto)vom', $\mathrm{BrVb}_{4}$ 92rb20);

(2) kratki oblici prošlih aktivnih participa i-glagola;

(3) 3. 1. mn. »jakoga« aorista;

(4) stari sigmatski aorist (pritěše);

(5) podudaranje oblika nominativa i akuzativa imenica za živo;

(6) adnominalni dativ;

(7) leksik (apostolikb [91vb20], erěi [92rb21], eterb [91vb20], idolb [92rb1], jemuns [92vb7], vija [92vb14]).

Međutim, treba reći da se ti navodni arhaizmi upotrebljavaju još i u XIII. stoljeću. Osim toga, u Žitiju ima inovacija koje Vajs nije zapazio i koje ću spomenuti kasnije.

Kod nominalnih (kratkih) oblika pridjevske deklinacije citira se samo jedan primjer, $H($ rbsto)vom' (Čtenie VI.). Međutim, kod posvojnih pridjeva kratka ili nominalna sklonidba je normalna. ${ }^{12}$

Kratki su oblici prošlih aktivnih participa i-glagola u kasnijim stoljećima razmjerno rjetki, ali su potvrđeni i u prijevodima iz XIII. stoljeća, usp.

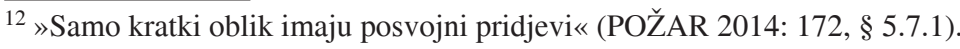


stvor'ša $\left(\mathrm{BrN}_{2} 384 \mathrm{~b} 12\right)$, prestupal'še (BrVO 411a; 1 Mak 2,2). ${ }^{13}$ Štoviše, ovi se oblici susreću čak i u prijevodima iz XIV. stoljeća, npr. u Pseudo-Jeronimovim pismima: povraĉ' se (CIvan 164v17), ostav(a)lb (CIvan 169v23), Vskoč' (CIvan 170r14).

Sljedeća kategorija kojoj se posvećujemo je tzv. »jaki« ili tematski aorist. Uzet ću primjere iz nove hrvatsko-crkvenoslavenske gramatike, i to iz II. novljanskoga brevijara $\left(\mathrm{BrN}_{2}\right)$, ali ne iz svetopisamskih perikopa. Citiram sljedeće primjere: idomb $\left(\mathrm{BrN}_{2} 401 \mathrm{c} 26\right.$; Homilia s. Hieronymi presbyt.); padu $\left(\mathrm{BrN}_{2} 129 \mathrm{~d} 31\right.$; Antifon $) ;$ srětu $\left(\mathrm{BrN}_{2} 424 \mathrm{a} 18\right.$; Johannes I. papa $) .{ }^{14}$ Ali i u ostalim mlađim prijevodima brevijara s latinskoga ponekad se nalazi tematski aorist, npr. u knjizi o Jobu: pridu (Job 1,6), ${ }^{15}$ iz'obretomb (Job 5,27), ${ }^{16}$ v'zmogb (Job 31,23), ${ }^{17}$ ob'rétu (Job 32,3). ${ }^{18}$

Stari je sigmatski aorist zastupljen jednim jedinim primjerom (pritěše). Međutim, i tekstologija i sintaksa daju naslutiti da ovaj oblik nije izvoran, već se pojavio kao posljedica naknadne redakcije teksta. Tekstološki to mjesto izgleda ovako:

$\mathrm{BrVb}_{4} 92 \mathrm{va} 27$ (narodb ...) pritěše $]=$ FgBerč 1.13, 19va13] BrVat 204vb13 priteče] BrLab 159rb20, BrKuk 136rb9-10 - confluens (omnis provincia)

U sintaktičkom pogledu množinska sročnost imenice narodb nije uobičajena i zato se čini da je naknadno uvedena.

Podudaranje oblika nominativa i akuzativa za živo u hrvatskoglagoljskim se tekstovima čuva razmjerno dugo. Citiram nekoliko primjera misnih oracija iz hrvatskoglagoljskoga misala koje su vjerojatno prevedene u XIII. stoljeću:

Vzbudi ...d(u)hb s(ve)ti (MVat ${ }_{4}$ 207ra; 543)

$\boldsymbol{D}(\boldsymbol{u}) \boldsymbol{h} \boldsymbol{b}$... tvoee ljubve v ni vlěi. (MVat ${ }_{4} 28 \mathrm{rb}, 109 \mathrm{vb}, 112 \mathrm{va}, 114 \mathrm{va}$; 1069.1.2.3.4)

Bl(agoslo)věm'o(tb)cb is(i)nb (MVat ${ }_{4}$ 89ra, Veliki četvrtak),

$\boldsymbol{D}(\boldsymbol{u}) \boldsymbol{h} \boldsymbol{b}$... tvoee ljubvi v ni vlèi. (MVat ${ }_{4} 261 \mathrm{va}$, Missa pro concordia fratrum)

13 BADURINA-STIPČEVIĆ 2006: 78.

${ }^{14}$ GADŽIJEVA; MIHALJEVIĆ 2014: 237-238.

${ }^{15}$ ZARADIJA-KIŠ 1997: 86.

${ }^{16}$ ZARADIJA-KIŠ 1997: 94.

${ }^{17}$ ZARADIJA-KIŠ 1997: 143.

${ }^{18}$ ZARADIJA-KIŠ 1997: 144. 
I adnominalni je dativ u novijim hrvatskoglagoljskim prijevodima uobičajen, kako to pokazuju sljedeći primjeri iz misnih oracija:

věrnim'd(u)šam' darovatelju (23.7. S. Apollinarius, Or. 225) - fidelium remunerator animarum

vsěm' věrnim' pastiru i pravitelju (Pro papa, Or. 239) - omnium fidelium pastor et rector

c(ěsa)ra c(ěsa)r(e)mb (25.8. S. Ludovicus rex Franciae, Or. 296) - Regis regum

vb otpuĉenie mrbtvim' (Pro pluribus defunctis, Secr. 603) - ad indulgentiam ... defunctorum

Kod leksika ograničavam se na riječi, koje su obrađene u objavljenim svescima hrvatskoglagoljskoga rječnika RCJHR I i RCJHR II (apostolikb, erěi, eterb, vija).

Riječ apostolikb tipična je za najstarije staroslavenske tekstove kao što su npr. Panonska žitija. Ali ako pogledamo u hrvatsko-crkvenoslavenski rječnik vidimo da se pojavljuje i u nekim brevijarima i misalima (RCJHR I: 72). Riječ viě 'vrat' (RCJHR I: 466) potvrđena je, doista, ponajprije u tekstovima koji su nastali u staroslavenskom razdoblju, ali i u mlađim tekstovima: Job, CPar, Epistola o nedjelji. Ni erěi (RCJHR II: 509-511) u korpusu hrvatskoglagoljskih spomenika nije ograničen samo na najarhaičnije tekstove, već se susreće i u mlađima. Iako rjeđe nego erěi, zamjenica eterb (RCJHR II: 516-517) također se često upotrebljava kako u arhaičnim, tako i u mlađim hrvatskoglagoljskim tekstovima.

U tekstu Žitija potvređeno je i nekoliko jezičnih inovacija:

(1) otb + gen. 'o': BrVb $491 \mathrm{rb} 25$ o- negože - de quo (ali: BrVb $492 \mathrm{ra} 5-6$ v pisměh'o Klim 'ntě; $\mathrm{BrVb}_{4} 92 \mathrm{va6}-8$ da o blagodarěh' ego vzraduem se - de beneficiis);

(2) instrumentalis absolutus: $\mathrm{BrVb}_{4} 92 \mathrm{vb6}$ učeĉim' Klimbn 'tom' - per sanctum clementem;

(3) sintaksa brojeva: $\mathrm{BrVb}_{4} 92 \mathrm{val} o^{t}$ šest' pbpriç $-a$ sexto milliario (MOMBRITIUS 1910, p. 344.3);

(4) leksik: očito 'publice' ( $\mathrm{BrVb}_{4}$ 91va13); sidro 'ancora' ( $\mathrm{BrVb}_{4}$ 93ra4; sidro je vjerojatno kasnija varijanta potvrđena u nekoliko rukopisa).

Ni gramatika ni leksik Klementova Žitija nisu u okviru hrvatskoglagoljskih tekstova ni u kojem slučaju tako arhaični kako je mislio Vajs. Tekst je mogao nastati tijekom XIII. stoljeća, što potvrđuje i nekoliko inovacijskih 
značajki kao što su prijedložna skupina otb + genitiv 'o', apsolutni instrumental, sintaksa brojeva, ali i neki mlađi leksemi.

\section{ZAKLJUČAK}

Kao zaključak o hrvatskoglagoljskom Žitiju pape Klementa I. valja reći sljedeće:

(1) Prijevod je Žitija vjerojatno nastao zajedno s nastankom hrvatskoglagoljskoga (franjevačkoga) brevijara u XIII. stoljeću.

(2) Hrvatskoglagoljski su tekstovi - za razliku od latinskih - razmjerno identični.

(3) Tekst $u \mathrm{BrVb}_{4}$ spada među one koji najbolje čuvaju izvorni prijevod Žitija, iako i s mjestimičnim izmjenama i pogreškama. Tekstološki mu je najbliži tekst u fragmentu Berčićeve zbirke (FgBerč).

(4) Nije moguće sastaviti pouzdanu stemma codicum.

(5) Dosada nisam uspio pronaći latinski izvornik. Najbliži su hrvatskomu tekstu - prema sadašnjim saznanjima - pojedini tekstovi iz venecijanskih izdanja brevijara, ali četvrto hrvatskoglagoljsko poglavlje nisam mogao naći ni u jednom latinskom brevijaru.

(6) Tekst je latinskoga brevijara sigurno već postojao u XII. stoljeću.

(7) Uvrštavanje brevijarskoga Žitija u apokrife nije opravdano. Unatoč tomu njegova je obradba u knjizi Aurelia de Santos Otera (DE SANTOS OTERO 1978) vrijedna, jer sadrži važan materijal.

Zadaće za buduća istraživanja Klementova Žitija u hrvatskoglagoljskim brevijarima su - potraga za njegovim latinskim izvornikom te s time u vezi i pitanje kada je nastao latinski brevijarski tekst.

\section{KRATICE IZVORA}

BrLab $=$ I. ljubljanski brevijar, kraj XIV. st., Ljubljana, Narodna in univerzna knjižnica, sign. Ms 161.

BrKuk = Kukuljevićev brevijar, 1485. g., Zagreb, Arhiv HAZU, sign. I 34 .

BrMav = Brevijar popa Mavra, 1465. g., Zagreb, Nacionalna i sveučilišna knjižnica, sign. $R 7822$.

$\mathrm{BrN}_{2}=$ II. novljanski brevijar, 1495. g., Novi Vinodolski, Župni ured.

BrOxf $=$ Oxfordski brevijar-misal, XIV. st., Oxford, Bodleian Library, sign. Ms. Canon Lit. 172. 
$\mathrm{BrPm}=$ Pašmanski brevijar, XIV./XV. st., Zagreb, Arhiv HAZU, sign. III b 10.

$\mathrm{BrPt}=$ Prvotisak brevijara, 1491. g., Venecija, Biblioteca Nazionale Marciana, sign. Inc. 1235.

BrVat $_{6}=$ Vatikanski brevijar Illirico 6, 1379. g., Rim, Biblioteca Apostolica Vaticana, sign. Borg. illir. 6.

$\mathrm{BrVb}_{4}=I V$. vrbnički brevijar, XIV. st., Vrbnik, Župni ured.

BrVO = Brevijar Vida Omišljanina, 1396. g., Beč, Österreichische Nationalbibliothek, sign. Cod. slav. 3.

CIvan = Ivančićev zbornik, XIV./XV. st., Zagreb, Samostan sv. Franje Ksaverskog.

CPar = Pariški zbornik, 1375. g., Pariz, Bibliothèque Nationale, sign. Slave 73.

FgBerč = List brevijara, XV. st., Sankt Peterburg, Rossijskaja nacional'naja biblioteka, Berčićeva zbirka, 1.13, l. 19.

FgKrk = List brevijara, XIV./XV. st., Krk, Arhiv bivše Staroslavenske akademije, br. 39.

MVat $_{4}=$ Vatikanski misal Illirico 4, druga polovica XIV. st., Rim, Biblioteca Apostolica Vaticana, sign. Borg. illir. 4.

\section{POPIS LATINSKIH IZVORA}

Breviarium $=\mathrm{XV}$. st. Zagreb, Arhivu HAZU, sign. I. a. 11 .

Breviarium de Camera secundum morem sanctae Romanae Ecclesiae - Venecija 1521. g.

Breviarium Ecclesiae cathedralis Zagrabiensis = XIII. st. Zagreb, Nacionalna i sveučilišna knjižnica, sign. $M R 67$.

Breviarium fratrum minorum $=\mathrm{XIV}$. st. Zagreb, Arhivu HAZU, sign. I. a. 8 .

Breviarium MR 29 = XIV./XV. st., Zagreb, Nacionalna i sveučilišna knjižnica, sign. MR 29.

Breviarium romanum $=$ Albi 1482. g., Beč, Österreichische Nationalbibliothek, sign. Ink 5.D.2.

Breviarium romanum $=$ Lyon 1559. g., Beč, Österreichische Nationalbibliothek, sign . 22.J.55.

Breviarium romanum = Venecija 1478. g., Beč, Österreichische Nationalbibliothek, sign . Ink 4.D.10.

Breviarium romanum = Venecija 1481. g., Beč, Österreichische Nationalbibliothek, sign. Ink 21.D.2.

Breviarium romanum optime recognitum = Venecija 1558. g., Beč, Österreichische Nationalbibliothek, sign. 22.G.51.

Breviarium s. Justina = XIII. st., Zagreb, Nacionalna i sveučilišna knjižnica, sign. MR 72/II

Breviarium Zagrabiense = XIV. st., Zagreb, Arhivu HAZU, sign. I. c. 42.

Breviarium Zagrabiense $=$ XIV./XV. st., Zagreb, Nacionalna i sveučilišna knjižnica, sign . MR 80. 


\section{LITERATURA}

ALTANER, B.; A. STUIBER. 1978/1993. Patrologie. Freiburg - Basel - Wien: Herder.

BADURINA, A. 1995. Iluminirani rukopisi u Hrvatskoj. Zagreb: Kršćanska sadašnjost - Institut za povijest umjetnosti.

BADURINA-STIPČEVIĆ，V. 2006. Knjige o Makabejcima u hrvatskoglagoljskoj književnosti: Prva knjiga o Makabejcima u hrvatskoglagoljskim brevijarima. Slovo 54/55: 5-126.

$\mathrm{BHL}=$ Bibliotheca hagiographica latina antiquae et mediae aetatis (= Subsidia Hagiographica, 6). 1898-1901 [reprint 1992]. Bruxelles: Société des Bollandistes.

CPG $=$ GEERARD, M. 1983-1987. Clavis Patrum Graecorum. I-V. Turnhout: Brepols.

CPL = DEKKERS, E.; Æ. GAAR (ed.). 1995. Clavis Patrum Latinorum. Editio tertia aucta et emendata. Steenbrugis: in Abbatia Sancti Petri: Brepols.

DE SANTOS OTERO, A. 1978. Die handschriftliche Überlieferung der altslavischen Apokryphen, I. Berlin - New York: De Gruyter.

EIS, G. 1933. Die Quellen für das Sanctuarium des Mailänder Humanisten Boninus Mombritius. Eine Untersuchung zur Geschichte der großen Legendensammlungen des Mittelalters. Berlin: Ebering. (= Germanische Studien, Heft 140)

FRERE, W. H.; L. E. G. BROWN. 1911. The Hereford Breviary. Edited from the Rouen Edition of 1505 with Collations of Manuscripts By Walter Howard Frere and Langton E. G. Brown, Vol. II. London: Henry Bradshaw Society.

FREDE, H. J. ${ }^{4}$ 1995. Kirchenschriftsteller. Verzeichnis und Sigel. Freiburg: Herder.

GADŽIJEVA, S.; M. MIHALJEVIĆ. 2014. Glagoli. M. Mihaljević (ur.). Hrvatski crkvenoslavenski jezik. Zagreb: Hrvatska sveučilišna naklada - Staroslavenski institut, 205-260.

HESBERT, R. J. 1963. Corpus antiphonalium officii. Vol. I: Manuscripti »Cursus romanus «, editum a Renato-Joanne Hesbert. Roma: Herder.

HESBERT, R. J. 1968. Corpus antiphonalium officii. Vol. III: Invitatoria et Antiphonae, editum a Renato-Joanne Hesbert. Roma: Herder.

KASHTANOV, D.; A. KOROLËV; A. VINOGRADOV. 2018. The Chronology of the Hagiographic Tradition of St Clement of Rome. A. Rigo; M. Trizio, E. Despotakis (ur.). Byzantine Hagiography. Texts, Themes \& Projects. Turnhout: Brepols, 201-220.

KNIEWALD, D. 1940. Zagrebački liturgijski kodeksi XI.-XV. stoljeća. Croatia sacra - Arkiv za crkvenu pivijest Hrvata 10: 1-128.

KOROLËV, A. A. 2014. Počitanie. Na Zapade. Kliment (I - nač. II v.), sščmč. = сщмч. (= священномученик), ep. Rimskij. Pravoslavnaja énciklopedija, Tom XXXV (Kiriopascha - Kloss). Moskva: Cerkovno-naučnyj centr »Pravoslavnaja ėnciklopedija«: 434-453.

LEISIBACH, J. 1978. Zur Leseordnung des Sittener Breviers im Mittelalter. Zeitschrift für Schweizerische Kirchengeschichte 72: 205-332.

MAÎTRE, C. 2015. Le bréviaire cistercien Troyes, Bibliothèque Municipale, MS 2030. Fribourg: Universitätsverlag Fribourg. (= Spicilegium Friburgense 46). 
MOMBRITIUS, B. 1910. Sanctuarium seu Vitae sanctorum. Curaverunt duo Monachi Solesmenses [D. A. Brunet et D. H. Quentin]. Parisiis: Fontemoing.

POŽAR, S. 2014. Pridjevi. M. Mihaljević (ur.). Hrvatski crkvenoslavenski jezik. Zagreb: Hrvatska sveučilišna naklada - Staroslavenski institut, 151-188.

RCJHR I = Rječnik crkvenoslavenskoga jezika hrvatske redakcije, I. svezak ( $\left.a^{1}-v r e ̂ d b\right)$. Zagreb: Staroslavenski institut, 2000.

RCJHR II = Rječnik crkvenoslavenskoga jezika hrvatske redakcije, II. svezak (vrêdbnb - zapovêdnica). Zagreb: Staroslavenski institut, 2015.

SAXER, V. 1994. Clemens v. Rom. Lexikon für Theologie und Kirche, Zweiter Band (Barclay bis Damodos). Freiburg - Basel - Rom - Wien: Herder, 1227-1228.

SOBOLEVSKIJ, A. I. 1912. Glagoličeskoe žitie sv. Papy Klimenta (I-III). Izvestija Otdelenija russkogo jazyka i slovesnosti 17/3: 216-222.

ŠTEFANIĆ, V. 1960. Glagoljski rukopisi otoka Krka. Zagreb: Jugoslavenska akademija znanosti i umjetnosti (= Djela JAZU, knj. 51).

TRENDAFILOV, Ch. 2003. Chersonska legenda. L. Graševa (glav. red.). Kirilo-metodievska enciklopedija. Tom IV $(T-J a)$. Sofija: Akademično izdatelstvo »Marin Drinov«, 384-388.

VAJS, J. 1911. Život sv. Klimanta pape u IV. vrbničkom misalu [sic!]. Starine 33: 565-571.

VAN DIJK, S. J. P. 1954. Some Manuscripts of the Earliest Franciscan Liturgy. Franciscan Studies 14/3: 225-264.

VJALOVA, S. O. 2000. Glagoljski fragmenti Ivana Berčića u Ruskoj Nacionalnoj biblioteci. 1. Faksimili; 2. Glagoličeskie fragmenty Ivana Berčiča: Opisanie. Zagreb: Hrvatska akademija znanosti i umjetnosti - Ruska nacionalna biblioteka - Staroslavenski institut.

WADDELL, Ch. 2007. The Primitive Cistercian Breviary (Staatsbibliothek zu Berlin, Preußischer Kulturbesitz., Ms. lat. oct. 402) with variants from the »Bernardine "Cistercian Breviary. Fribourg: Universitätsverlag Fribourg. (= Spicilegium Friburgense 44).

www.manuscripta.at

ZARADIJA-KIŠ, A. 1997. Knjiga o Jobu u hrvatskoglagoljskoj književnosti. Zagreb: Matica hrvatska. 


\section{PRILOG}

\section{TEKST KLEMENTOVA ŽITIJA IZ IV. VRBNIČKOGA BREVIJARA ${ }^{19}$}

Čtenie I. Klimbn'tь ot negože $\mathrm{P}(\mathrm{a}) \mathrm{v}(\mathrm{a}) \mathrm{lb}$ ap(osto)lı k pilipisiem' piše g(lago)letb S Klim'nstom' is pročimi dělateli (91va) moimi ihže imena pisana sutb v knigahь života. četvr'ti bisk(u)pь. po bl(a)ž(e)něem' Petrě. Obače Linь papa drugi bistь. treti že Anaklet'. acee si i mnozěhь latin'skihь druzěhь za Petrom' ap(osto)loms mnets bivše. prěžde Kliman'ta pisa ot těla rimske cr'kve k cr'kvi korentskoi. zělo prospěšnu ep(isto)liju ěže oĉe v mnozěhь městěhь očito čtet' se. ěžě (!) mně videt se kar'terice ep(isto)lie ěže pod' imenemb ap(osto)la P(a)vla vidit' se podobna.

Čtenie II. Kliman't' rodom' rimlanin $o^{t}$ strani Celie gori o ${ }^{t} \mathrm{o}(\mathrm{tb}) \mathrm{ca}$ Fauština sědě lět' .z. (=9) m(ě)s(e)ca .b. (=2) d(b)ne .i. (=10). Bistь že vb vrěme Galba i Vespesiěna $o^{t}$ sudbstva Tragala i Italika. daže do devetago Vespesiěna $i$ Tita. Si egda mnogie knigi ljubviju věrě h(rbst)ьěn'skoi čes( $91 \mathrm{vb}) t i$ pisal bě mukoju věnča se.

Čtenie III. Si stvori v sedım stranь razděti (!) pisci izbrane věrne crkve-

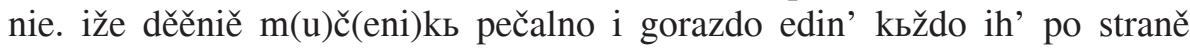
svoei ljubitelno iz'obreĉet' Si stvori dvě ep(isto)lii, iže katolicě naricaeta se. Si zap(o)vědiju b(la)ž(e)n(a)go Petra priět' cr(b)kv i stroenie arhierěistva ěkože bě emu o ${ }^{t} \mathrm{~g}$ (ospod)a Is(u)h(rbst)a stol' prědan' ili prěporučen' tako v

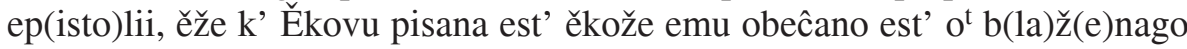
Petra $\operatorname{cr}(\mathrm{b}) \mathrm{k}(\mathrm{b}) \mathrm{vb}$ obreĉeši.

Čtenie IV. Klimsnt' ap(osto)likb etera muža prošeniem' ženi ego Těodora oslěpbl'ša i oglbg'ša (!) za prěgrěšenie ego zdrava stvoriv. i pročaě čudesa mnoga tvoraše $b(l a) z ̌(e) n i ~ K l i m s n b t ' v$ gradě Rimě ěkože $v$ pročihs měs (92ra) (rasura) městěh' plıněe pisano est. Potom' posla Antiěn' listi k Troěnu c(ěsa)ru i vbzvěsti emu vsa stvoreniě v pisměh' o Klim'ntě.

${ }^{19}$ Glagoljski se tekst transliterira po pravilima uobičajenim u časopisu Slovo Staroslavenskoga instituta. Samo u dva slučaja pridržavam se starijega uzusa: $\mathbb{8}$ se transliterira kao $\check{e}$ (a ne kao $\hat{e}$ ), a Il se transliterira kao ju (a ne kao $\hat{u}$ ). 
Čtenie V. Pisanie že sice g(lago)laše. vižd' c(ěsa)ru ěko Klimsnt' ezik' naš' sbblažnaet'. i narod' svědětela na nь obrěsti ne možet'. Togda Troěn' napisa list' k Tiěnu (!) reki. dostoit' emu ili povinuti se b(o)gom' n(a)š(i)mb. ili na onь polь mora pustinıskago vezenu biti priležeĉu her'sonsku gradu. İ egda Troěn' povelěnie sie utvr'di pomišlaše Mamertin' da bi Klimsn'tb volna zavezeniě ne prosilı na pače b(ogo)mb da požr'l' bi. B(la)ž(e)ni že Klimsn't' podvizaše se i samogo sudiju na veru H(rbsto)vu obratiti. i sam' pače izvoli zavezenie lju(92rb)biti neže požrěti idolom'.

Čtenie VI. Veliku že blagodět' g(ospod)b Klimsn'tu tako poda ěko plakati se sudiju stvori i g(lago)lati. b(og)ь emuže ti vsěm' sr(bdb)cem' služiši pomozi vsěm' napisanim' o zemli zaslaniě. I nareče korabbl'. ne tskmo ti nь i ljudi mnozi o věrnih' muži idu. Egdaže doidu města v dělě trınii i mramorniem' bole dvu tisuĉu h(rıst)běn' obrětu. Dtıgo (!) lěts napisaniem' osueni iže uzrěše s(ve)t(a)go Klimsnta vsi edinod(u)šno prěd nim' plačuĉe g(lago)lahu. Moli za ni b(la)ž(e)ni Klimsn'te erěju H(rbsto)vb. da dostoini budem' obeĉaniem' $\mathrm{H}$ (rbsto)vom'.

Čtenie VII. On že otveĉa. ne moimi utežani g(ospod)b posla me k vam'. i vašimb oběn'čanim' pričestna me stvori. utěšenie trbpěniě podav' im' ra(92va)zumě ěko o ${ }^{t}$ šest' pьpriĉs na pleĉih' vodu nošahu. I reče molěte se vsi k' g(ospode)vě da o ${ }^{t} v r^{\prime} z e t$ ' $\mathrm{m}(\mathrm{u}) \check{c}(\mathrm{eni}) \mathrm{kom}$ ' i ispovědnikom' svoim' istočnik' blagi. da o blagodarěh' ego vzraduem se. I paki reče proražbi kamen' v pustini sinaiscě Moisěem' izvedı vodu. tbžde nam' neprěstajucee vodi podai. Moleĉu že se s(ve)tomu Klimsn'tu ěvi se emu agnьc' b(o)ži.

Čtenie VIII. Egdaže m(o)l(i)tvb isplsni. v'zrěv' vidě na gorě agnьc' b(o)ži stoeĉ'. Pod negože nogoju istočnikb živ' isteče. iděže vidě agncь stoeĉb. tu iskopaše vodu sam' že udari motikoju tri krat'. togda sbist' se pěnie. Rěčna ustr'mleniě veselet gradı b(o)ži (Ps 45,5). Sego radi že sluha čudes' narodь per'hi (!) pritěše. i ssbraše se mnozi kb s(ve)tomu (92vb) Klimsn'tu i obratiše se kb g(ospod)u na veru nevěrnih' sedm' deset' i pet'. Pride že sl(o)vo sie k Troěnu c(ěsa)ru. ěko rastet' kr'st'ěn'stvo učeĉim' Klimbn'tom'. I posla Afiěna i jemuna ěže mnogie kr'st'ěni prognasta. svět' stvor'ša pogubiti Klimbn'ta. Rěsta že voem' svoimb. em'še vezěte i na glubinu mora. i navezavše na viju ego ankoru železnu. i tako vr'zěte i v more. Da ne vzmogut' k tomu kr'st'ěne $v$ město $b(o g)$ a čisti ego.

Čtenie IX. Sim že bivajuĉem' stoěhu mnozi h(rbst)běne na brězě mora plačuĉe se. K nimže rěsta uč(e)nika ego Pěbs i Kor'něl'. molěmo se vsi k g(ospod)u da ěvit' nam' s(ve)t(a)go Klimbn'ta m(u)č(eni)ka svoego. Ï moleĉim' se imb otvr'ze se more i obrětu e v činu hrama mramorna. 
anĵelskimi ruka(93ra)mi ugotovanu i tu v racě položeno tělo ego uč(e)n(i)ka b(la)ž(ena)go Petra ap(osto)la i sidro v krai raki ležeĉe š nim'že vbvr'žen' bě v more. I vi (!) se učenikoma ego ne vzeti i. imže vprorečeno bis(tb) drugoe lěto mučeniě ego. i tu puts g(ospod)ь po suhu ugotova sedьm’ d(b)ni. v hvalu svoju. Potom' daže i do sego dne vb obhodno lěto bivaet' takožde. I togo radi suĉei okrbst' věrovaše v' g(ospod)a n(a)šego Is(u)h(rbst)a. egože propovědě ims Klimbn'tь.

Resumee

Johannes Reinhart

\section{DIE KROATISCH-GLAGOLITISCHE BREVIER-VITA VON PAPST CLEMENS I.}

Die Vita von Papst Clemens I. ist in einer beschränkten Anzahl von kroatisch-glagolitischen Brevieren bezeugt. Sie wurde zwei Mal nach einem der ältesten Textzeugen, dem 4. Brevier von Vrbnik (XIV. Jh.), ediert, einmal von Josef Vajs (1911) und einmal von Sobolevskij (1912). Daneben ist die Vita in den folgenden Brevieren bzw. Brevier-Fragmenten vorhanden: Brevier Illirico 6 (Mitte/drittes Viertel des XIV. Jh.), Brevier von Ljubljana (Ende des XIV. Jh.), Pašman-Brevier (XIV./XV. Jh.), Brevier-Missal Nr. 172 aus Oxford (XIV. Jh.), Brevier des Mavar (1465), Kukuljević-Brevier (1485), gedrucktes Brevier (1491); Fragment eines Breviers (XIV./XV. Jh.; Krk, Nr. 39), Brevier-Blatt (XV. Jh.; Berčićeva zbirka 1.13, f. 19). In manchen dieser Textzeugen sind nicht alle neun Lesungen der Vita bezeugt.

Sobolevskij nahm in seinem Artikel zu Recht an, dass das Original des slawischen Textes in einem lateinischen Brevier zu finden sein müsse. Vajs publizierte den lateinischen Text aus einem zeitgenössischen Brevier, der jedoch vom kroatisch-glagolitischen Text wesentlich abweicht. Die Überprüfung von ungefähr zwei Dutzend Handschriften und Altdrucken des lateinischen Breviers in Wien und Zagreb förderte leider noch kein genaues Original des kroatisch-glagolitischen Textes zutage. Der am ehesten in Frage kommende Text findet sich im Breviarium de Camera secundum morem sanctae Romanae Ecclesiae (Venedig 1521), der auch im kroatisch-glagolitischen Wörterbuch in Zagreb benützt wird.

Vajs betonte in seinem Artikel eine Reihe morphologischer (z.B. archaische Aoriste), syntaktischer (Nominativ/Akkusativ, adnominaler Dativ) sowie lexikalischer (apostolikb, eterb) Archaismen des Textes (»da stavimo ovaj tekst uporedo sa najstarijim glagolskim tekstovima uopće «). Da die Vita jedoch auch etliche grammatische Innovationen (z.B. Instrumentalis absolutus) und typisch kroatische Lexeme (z.B. očito Ipublicel 'öffentlich'; otb + Genitiv 'o', 'über') enthält, kann man annehmen, dass die Vita am Ende des XIII. oder zu Beginn des XIV. Jahrhunderts übersetzt wurde.

Schlüsselwörter: Papst Clemens von Rom, kroatisch-glagolitische Breviere, lateinisches Original, die Breviervita von Papst Clemens I., sprachliche Archaismen, sprachliche Innovationen, Entstehungszeit der kroatisch-glagolitischen Breviervita von Clemens. 


\section{Summary}

\section{Johannes Reinhart}

\section{THE CROATIAN GLAGLOLITIC BREVIARY VITA OF POPE CLEMENT I.}

The Life of Pope Clement I is preserved in a limited number of Croatian Glagolitic breviaries. It was published twice according to one of the oldest texts, from the 4th Vrbnik Breviary (14th c.), once in the edition of Josef Vajs (1911), and the second time in the edition of Sobolevskij (1912). In addition, the Žitije is preserved in the following breviaries or fragments of breviaries: Breviary Illirico 6 (middle/third quarter of 14th c.), Ljubljana Breviary (end of 14th c.), Pašman Breviary (14th/15th c.), Oxford Breviary-Missal Nr. 172 (14th century), Breviary of Mavar (1465), Kukuljević Breviary (1485), Printed Breviary (1491), Breviary Leaf (14th/15th c., Krk, No. 39), Breviary Leaf (15th c., Berčić Collection 1.13, f. 19). All of the nine lessons of the breviary Vita are attested in only some of these texts.

Sobolevskij rightly stated in his paper (1912) that the original of the Slavonic text must be found in some Latin breviary. Vajs (1911) published a Latin text from a contemporary breviary which, however, cannot be the original of the Croatian Glagolitic translation. Unfortunately, an exact Latin original of the Croatian Glagolitic Vita has not yet been found. Some of the lessons are attested in late medieval printed breviaries. The Breviarium de Camera secundum morem sanctae Romanae Ecclesiae (Venice 1521), which is used in the Croatian Church Slavonic Dictionary, contains nearly all readings of the Croatian Glagolitic Vita. However, not only does it have some surplus texts, its text is also divided up into different readings.

In this paper an attempt is made to determine the time of the translation of the Vita. Vajs emphasized a few morphological (e.g., archaic aorists), syntactic (nominative/accusative, adnominal dative) and lexical (apostolikb, eterb) archaisms in the Croatian Glagolitic text (»da stavimo ovaj tekst uporedo sa najstarijim glagoljskim tekstovima uopće «). However, it seems doubtful whether the translation dates from a very ancient period. The Vita contains several grammatical innovations (e.g., the Instrumentalis absolutus) and some Croatian lexemes which are attested relatively late (e.g., očito 'in public'; otb + genitive 'about'). Therefore, it must be surmised that the Vita was translated not earlier than during the 13th century or at the beginning of the 14th century.

Keyw ords: Pope Clement of Rome, Croatian Glagolitic breviaries, Latin original, Breviary Vita of Pope Clement I., linguistic archaisms, linguistic innovations, origin of the translation of the Croatian Glagolitic Vita.

Johannes Reinhart

Wien (Austria)

johannes.reinhart@univie.ac.at 